\title{
Effects of the addition of water-filled bladders or volatile fatty acids to the rumen on the feeding behaviour in lactating dairy cows at different stages of lactation
}

\author{
P Faverdin, T Aubert, JL Peyraud, BP Widyobroto
}

INRA, station de recherches sur la Vache laitière, 35590 Saint-Gilles, France

\begin{abstract}
Effects of volatile fatty acids (VFA) infusions on dry matter intake (DMI) differ in lactating compared to dry cows (Faverdin, 1990). The objective of this experiment was to measure the effects of satiation signals produced in the rumen on the feeding behaviour of dairy cows throughout lactation.
\end{abstract}

Two satiation tests (rumen bladders and VFA infusion) were carried out at $4,9,15$ and 35 wk after calving in 4 lactating dairy cows fitted with rumen cannula. Each test consisted of a sequential comparison of $\mathrm{DMl}$ and eating rate between $3 \mathrm{~d}$ of control and $3 \mathrm{~d}$ of treatment, with 3 $\mathrm{d}$ rest between the 2 tests. In the first test, the effect of the reduction of rumen volume by a 20I water-filled bladder (WFB) was compared to a bladder-free control. In the second test, a continuous infusion of $20.3 \mathrm{MJ} / \mathrm{d}$ volatile fatty acid (VFA) mixture (acetic/propionic/butyric acids, $10.8,3.37,2.55 \mathrm{~mol} / \mathrm{d}$ respectively) into the rumen was compared to a control infusion $(7 \mathrm{~g}$ $\mathrm{NaCl}, 3.7 \mathrm{~g} \mathrm{KCl}$ and $2.4 \mathrm{ml} \mathrm{HCl} 2 \mathrm{~N}$ per I water) with the same volume, $\mathrm{pH}$ and osmolality characteristics (50 I, 2.8, $340 \mathrm{mosm} / \mathrm{l}$ respectively). A mixed pelleted diet $(0.97 \mathrm{FUm}$ and $164 \mathrm{~g}$ of $\mathrm{CP} / \mathrm{kg} \mathrm{DM}$ ) was offered ad libitum once daily.

The DMI of the control remained relatively constant $(20.7 .21 .7 .21 .3,19.7$ for wk 4, 9,15 and 35 respectively). VFA infusion induced a significant decrease in DMI $(-1 \mathrm{~kg} \mathrm{DM} / \mathrm{d}, P<0.05)$ which remained constant from the beginning to the end of lactation. DMI was not decreased by VFA infusion during the first meal but decreased later in the day. WFB significantly reduced DMI by $2.3 \mathrm{~kg} / \mathrm{d}(P<0.05)$. This effect did not differ significantly between the 4 periods $(P>0.1)$, but tended to be more important during wk 4 than later on $(2.9,1.6,2.2,2.3$ for wk $4,9,15$ and 35 respectively). The response was similar over the $3 \mathrm{~d}$ of the test. The decrease in DMI was mainly due to a reduction in intake during the first meal and the first $h$ after distribution. However, the initial eating rate (IER) (10 or 20 first $\mathrm{min}$ ) was not affected by rumen fill. Thus, the increase in IER observed throughout the first months of lactation in this and a previous experiment (Faverdin, 1985) cannot be due to a rumen volume effect. Total rumination duration was not significantly increased by the presence of WFB (+19 $\mathrm{min}, P>0.1)$. This experiment suggests that the metabolic and physical satiation processes remain relatively constant throughout lactation.

Faverdin P (1985) Thèse de doctorat, Ing Sci Agro, Inst Natl Agron, Paris-Grignon

Faverdin P (1990) Reprod Nutr Dev suppl 2, 213s-214s 